\title{
PERSUADIR PARA NEGOCIAR \\ Y PACTAR PARA GANAR
}

TÁCTICAS MULTICULTURALES Y DE ALTO IMPACTO

PARA TRIUNFAR EN LAS DISCUSIONES *

Ana Cristina Gutiérrez

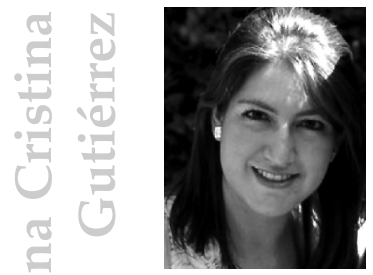

Estudiante de la Licenciatura en Pedagogía. Presidenta del Consejo de Alumnos, Escuela de Pedagogía, Universidad Panamericana. Autora de la reseña «Educar hij@s interactiv@s»de Fernando García Fernández y Xavier Bringué Sala. Revista Panamericana de Pedagogía, número 15, 2009.

Correo electrónico: [anacrisga@hotmail.com].

La obra Persuadir para negociar y pactar para ganar, expone de manera clara y concisa las diferentes formas de lograr una persuasión adecuada al momento de entablar una discusión. El objetivo principal es el de preparar al lector de tal modo que éste sea capaz de salir triunfante en sus discusiones.

La pertinencia de esta publicación y su vinculación con la educación, radica en que la persuasión se plantea como una competencia que deben desarrollar las personas. En el siglo que vivimos, es importante ser capaz de desenvolverse en cualquier ámbito, pues muchas situaciones del día a día requieren de negociación.

El doctor Aguirre sostiene que la persuasión es una actividad, una acción más que un producto determinado de la negociación; implica todo un proceso recíproco entre los participantes.

* Jorge F., Aguirre Sala, Persuadir para negociar y pactar para ganar, CONACYT/Universidad de Monerrey, México, 2008. 
Parte de la tesis del autor es que la comunicación no verbal juega un papel vital en las discusiones. La mirada, la postura, los gestos y los ademanes son componentes esenciales que ayudan a que la persuasión se lleve al cabo de manera exitosa o no. La mirada es un aspecto al que se debe prestar especial atención y hacerse consciente de cómo es que se utiliza, puesto que una mirada baja puede significar modestia o inseguridad, mientras que un contacto visual adecuado con el público puede garantizar el éxito. Esto es lo que algunos nominan como el lenguaje corporal o paralenguaje.

Otro aspecto que menciona como fundamental al momento de una negociación son los medios, como por ejemplo, el espacio físico. Éste debe tratarse con extremo cuidado, de manera tal que propicie una discusión fructífera. Aguirre menciona algunas sugerencias, como la posición de la pantalla y la posición del orador hacia ella, pues muchos oradores giran su cuerpo hacia la pantalla y descuidan a su público, ocasionando así una «barrera» entre ellos. Por otro lado, se argumenta sobre el espacio personal, es decir, el negociante no debe invadir el espacio del otro, pues acercársele demasiado puede incomodarlo a tal grado, que éste olvide por completo la negociación, se altere y no se logre la persuasión.

En el libro se ofrecen algunas recomendaciones sobre cómo elaborar una presentación para una negociación, entre muchos consejos, destaca el que no debe estar saturada de información ni sobrecargada de texto, pues esto sólo ocasionará que el público divague y pierda el interés. El autor menciona, como punto focal, que no hay que perder de vista que la negociación siempre debe centrarse en la gente y no en los medios.

Emplear el lenguaje correcto también es de vital relevancia al momento de persuadir. Una persona que emplea de manera errónea el lenguaje, pierde de inmediato la credibilidad. Además, los titubeos y muletillas son tan molestos que llevan al público a desatender lo que se está analizando, centrándose más bien en el cómo se está argumentando. Divagar en el discurso tampoco es una buena estrategia, lo óptimo es poseer un estilo conciso, utilizando palabras cortas y simples, asegurando la comprensión de quien se busca persuadir. 
Aunado al lenguaje está la voz. La entonación es importante; enfatiza puntos clave del diálogo, por ejemplo.

La apariencia personal y la forma de vestir son claves en la persuasión, pues éstas son estímulos no verbales que causan buenas o malas impresiones en el público, condicionando su respuesta.

Lo que resulta realmente esencial para llevar a cabo un proceso de persuasión es la empatía. El doctor Aguirre considera la empatía como un ingrediente poderoso que asegura el éxito del proceso. Esto es debido a que la empatía es un sentimiento de afinidad con el otro, es decir, se logra una identificación tal que ésta lleva al convencimiento.

Mucha gente confunde la persuasión con la discusión, sin embargo, la persuasión es mejor que la discusión, puesto que la primera implica un proceso dialógico - asegura el autor- e incluso titula así a la tercera parte del libro. Los argumentos que sostienen esta tesis son básicamente que la persuasión penetra mucho más al público que una mera discusión, puesto que se orienta a las actitudes y al comportamiento de los receptores. La persuasión tiene la capacidad de influir mental, afectiva y cognitivamente en los destinatarios del mensaje. Si una persuasión está bien estructurada se traducirá en un cambio de actitud o de comportamiento en las personas. Es por ello que quien es bueno persuadiendo, debe estudiar las pasiones humanas $\mathrm{y}$, a partir de ellas, llevar a cabo el proceso.

El doctor Aguirre sustenta que, al momento de la negociación, hay que ser muy creativos para formular alternativas si se necesitaran realizar de manera inmediata; para ello es recomendable tomar en cuenta lo que él denomina las tres «T», que son: territorio, tema y tiempo.

En el libro se sugieren algunos lineamientos para improvisar alternativas al momento de persuadir:

- Estar preparado. Es decir, familiarizado con el entorno y con la temática.

- Maximizar las alternativas. Tener flexibilidad en los caminos para llegar al objetivo principal. 
- Negociar con la persona adecuada. Es decir, hacerlo con quien esté capacitado para tomar una decisión, sin que se tenga que pedir autorización de un superior para ello.

- Concederse un margen de maniobra. Esto se refiere a pedir algo más de lo que se desea obtener.

- No ceder demasiado, ni demasiado de prisa.

- Estar preparado para decir «no». Si la negociación no va bien, más vale negarse, pero no basta decir «no», hay que dar argumentos que sostengan el porqué se reacciona así.

- Convertir la palabra en un vínculo. Es decir, nunca incumplir un acuerdo y, en caso de haber cometido un error, disculparse y enmendarlo. Así se crea confianza y vínculos entre las partes negociantes.

Casi al final del libro se exponen, de manera clara y puntual, los puntos clave a evitar en una negociación: interrumpir, marcar ventajas propias, atacar, acusar y hablar excesivamente. Por otro lado, está lo que debe procurarse: escuchar, pedir aclaraciones, resumir neutralmente los temas, buscar señales, entre otras.

Al final de la obra se ofrecen una serie de ejercicios para que el lector aplique los conocimientos adquiridos a través de la lectura. El autor logra, de manera didáctica, explicar el proceso de la negociación y las maneras de llevarlo al cabo y, justamente, esta aportación resulta enriquecedora en el proceso de enseñanza -aprendizaje. 